\title{
Changing patterns of cancer incidence in the early- and late-HAART periods: the Swiss HIV Cohort Study
}

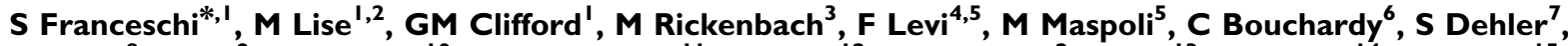

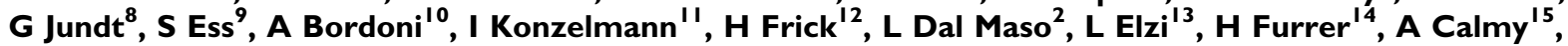 $M$ Cavassini $^{16}$, B Ledergerber ${ }^{17}, 0$ Keiser $^{18}$ and the Swiss HIV Cohort Study ${ }^{19}$}

'International Agency for Research on Cancer, 150 cours Albert Thomas, 69372 Lyon cedex 08, France; ${ }^{2}$ Epidemiology and Biostatistics Unit Aviano Cancer Center, Via Franco Gallini 2, 33081 Aviano, Italy; ${ }^{3}$ Coordination and Data Center, Swiss HIV Cohort Study, Mont-Paisible I6, CHUV, I0II Lausanne, Switzerland; ${ }^{4}$ Cancer Registry of the Canton of Vaud, CHUV Falaises I, 1011 Lausanne, Switzerland; ${ }^{5}$ Cancer Registry of the Canton of Neuchatel, Ave des Cadolles, 2000 Neuchatel, Switzerland; ' ${ }^{6}$ Cancer Registry of the Canton of Geneva, Bd de la Cluse 55, I 205 Geneva, Switzerland; ${ }^{7}$ Cancer Registry of the Canton of Zurich, Vogelsangstr. 10, 809I Zurich, Switzerland; ${ }^{8}$ Cancer Registry of Basel, Schönbeinstr. 40, 4003 Basel, Switzerland; ${ }^{9}$ Cancer Registry of St Gallen and Appenzell, Flurhofstr. 7, 9000 St Gallen, Switzerland; ${ }^{10}$ Cancer Registry of the Canton of Ticino, 6604 Locarno, Switzerland; "Cancer Registry of the Canton of Valais, Av Grand Champsec 86, 1950 Sion, Switzerland; ${ }^{12}$ Cancer Registry of the Canton of Graubunden, Lostr. 170, 7000 Chur, Switzerland; ${ }^{13}$ Division of Infectious Diseases and Hospital Epidemiology, University Hospital Basel, Petersgraben 4, 4031 Basel, Switzerland; ${ }^{4}$ Division of Infectious Diseases, University Hospital, University of Bern, Inselspital PKT2B, 3010 , Bern, Switzerland; ${ }^{15}$ Division of Infectious Disease/HIV Unit, University Hospital Geneva, Rue Micheli-Du-Crest 24, 1205 Geneva, Switzerland; ${ }^{16}$ Division of Infectious Diseases, University Hospital Lausanne, Rue du Bugnon 4, 1011 Lausanne, Switzerland; ${ }^{17}$ Division of Infectious Diseases and Hospital Epidemiology, University Hospital Zurich, University of Zurich, Rämistrasse 100, 8091 Zurich, Switzerland; ${ }^{18}$ Institute of Social and Preventive Medicine, University of Bern, Finkenhubelweg 1, 3012 Bern, Switzerland

BACKGROUND: The advent of highly active antiretroviral therapy (HAART) in 1996 led to a decrease in the incidence of Kaposi's sarcoma (KS) and non-Hodgkin's lymphoma (NHL), but not of other cancers, among people with HIV or AIDS (PWHA). It also led to marked increases in their life expectancy.

METHODS: We conducted a record-linkage study between the Swiss HIV Cohort Study and nine Swiss cantonal cancer registries. In total, 9429 PWHA provided 20615, 17690, and 15410 person-years in the pre-, early-, and late-HAART periods, respectively. Standardised incidence ratios in PWHA vs the general population, as well as age-standardised, and age-specific incidence rates were computed for different periods.

RESULTS: Incidence of KS and NHL decreased by several fold between the pre- and early-HAART periods, and additionally declined from the early- to the late-HAART period. Incidence of cancers of the anus, liver, non-melanomatous skin, and Hodgkin's lymphoma increased in the early- compared with the pre-HAART period, but not during the late-HAART period. The incidence of all non-AIDS-defining cancers (NADCs) combined was similar in all periods, and approximately double that in the general population. CONCLUSIONS: Increases in the incidence of selected NADCs after the introduction of HAART were largely accounted for by the ageing of PWHA.

British Journal of Cancer (2010) I 03, 4I6-422. doi:10.1038/sj.bjc.6605756 www.bjcancer.com

Published online 29 June 2010

(c) 2010 Cancer Research UK

Keywords: HIV; HAART; age; incidence rates; Switzerland

The introduction of highly active antiretroviral therapy (HAART) in 1996 has greatly influenced the pattern of cancer incidence in people with HIV or AIDS (PWHA). The decrease in the prevalence of severe immunodeficiency has resulted in a rapid reduction in Kaposi's sarcoma (KS) (Ledergerber et al, 1999; Franceschi et al, 2008; Polesel et al, 2008) and non-Hodgkin's lymphoma (NHL) incidence (Polesel et al, 2008; The COHERE Study Group, 2009). However, improved PWHA survival has been accompanied by an

*Correspondence: Dr S Franceschi; E-mail: franceschi@iarc.fr

${ }^{19}$ The members of the Swiss HIV Cohort Study are listed in the Appendix.

Received 20 April 20I0; revised 2I May 20I0; accepted I June 20I0; published online 29 June 2010 increase in the burden of non-AIDS-defining cancers (NADCs) (Engels et al, 2008).

The Swiss HIV Cohort Study (SHCS) is a large prospective cohort that has been ongoing for 20 years and is characterised by detailed follow-up information, excellent treatment standards, and the possibility to link with population-based cancer registries. As such, it offers an especially good opportunity to monitor changes in the pattern of cancer incidence in PWHA (Clifford et al, 2005; Franceschi et al, 2008; Polesel et al, 2008). It is now possible to add four additional years of follow-up to our linkage study of the SHCS and Swiss cancer registries, and thus to evaluate the long-term consequences of HAART use, particularly with respect to NADCs.

The aim of our present report is to evaluate the changes in patterns of cancer incidence in the SHCS in three different periods 
(pre-HAART, 1985-1996; early HAART, 1997-2001; and late HAART: 2002-2006), while taking into account large shifts in the age distribution of PWHA.

\section{MATERIALS AND METHODS}

The SHCS has been enrolling PWHA who are $>16$ years of age from seven large hospitals in different Swiss cities (Basel, Bern, Geneva, Lausanne, Lugano, St Gallen, and Zurich) since 1988, with some retrospective enrolment going back to 1985 (The Swiss HIV Cohort Study, 2010). Once written informed consent is obtained, detailed information (including demographic and clinical characteristics) is collected. Follow-up visits are scheduled at 6-month intervals and include updating information on selected disease diagnoses, laboratory test results, and HIV/AIDS-related treatments. Only AIDS-defining cancers (KS, NHL, and, since 1993, invasive cervical carcinoma) (Ancelle-Park, 1993) and Hodgkin's lymphoma have been systematically reported in the SHCS since the beginning of the study.

Nine active cancer registries, covering $56 \%$ of the Swiss population, collect population-based quality-checked data on cancer incidence in Switzerland (Curado et al, 2007). The Cancer Registries of the Cantons of Basel, Geneva, St Gallen and Appenzell, Ticino, Vaud, and Zurich overlap directly with six of the seven regions covered by SHCS centres (all except the Bern SHCS Centre) (Clifford et al, 2005).

Swiss cancer registries vary greatly both in size of population coverage (from 165000 in Neuchatel to 1168000 in Zurich) and year of initiation of cancer registration (from 1970 in Geneva to 1996 in Ticino). Routine indicators of data completeness and quality in the Swiss registries are very good (Parkin et al, 2002; Curado et al, 2007).

Record linkage was performed using an upgraded version of an ad hoc software application that was previously designed and validated in Italy and Switzerland (Geneva) to match individuals from AIDS and cancer registries while protecting patient anonymity (Dal Maso et al, 2001; Clifford et al, 2005). Each SHCS centre holds its own nominal participant records. Thus, each SHCS database was independently matched with the corresponding cantonal cancer registry. Furthermore, to account for inter-cantonal migration and health-care mobility, cross-cantonal linkage within neighbouring cancer registries, including those that do not overlap with SHCS centres (i.e., Neuchatel, Valais, and Glarus Graubunden), was also conducted. Personal identifiers were never made visible during linkage procedures, nor were they included in the output file.

From January 1985 through May 2007, 14560 PWHA (median age, 33 years; $95 \%$ range, $22-54)$ were enrolled in the SHCS. PWHA were excluded (in hierarchical order) from this report if they: (1) did not report a legal residence in a canton covered by a cancer registry with which their SHCS records were linked ( $n=4512$, principally those from the Bern SHCS Centre); (2) were followed by a private physician and were unavailable for name-based linkage $(n=60)$; (3) their follow-up in the SHCS did not correspond to years for which data were available in cancer registries $(n=520)$; or $(4)$ were $<16$ years $(n=4)$ or $>69$ years of age $(n=35)$ at enrolment. Eventually, 9429 PWHA (median age, 32 years; 95\% range, 22-53) were included. Of these, $29 \%$ were women and $18.1 \%$ had AIDS at study entry. For each PWHA included in the study, the relevant time period for the calculation of person-years at risk began 3 months after the date of SHCS enrolment and ended at 70 years of age, the date of last SHCS information, cancer diagnosis, or death, whichever was earliest.

Observed cancers included incident cases reported to cancer registries during the above-defined person-years at risk. In all, 103 cases of KS, 23 NHL, 3 invasive cervical carcinomas, and
10 NADCs diagnosed between 0 and 3 months after SHCS enrolment were considered prevalent cases and were not included. Cancers were classified according to the International Classification of Diseases for Oncology, Third Edition (Fritz et al, 2000), and according to the International Classification of Diseases and Related Health Problems, 10th Revision (World Health Organisation, 1992).

This study was approved by the ethics committees of the SHCS and the International Agency for Research on Cancer. All patients in the SHCS gave written informed consent.

\section{Statistical methods}

Expected numbers of cancers were computed from cancer registry-, sex-, age-, and period-specific incidence rates (IRs) (Parkin et al, 1992, 1997, 2002; Curado et al, 2007) for three periods (pre-HAART, 1985-1996; early HAART, 1997-2001; late HAART, 2002-2006). Observed numbers of cancers in PWHA were compared with expected numbers by standardised incidence ratios (SIRs). Corresponding 95\% confidence intervals (CIs) were computed using the Poisson distribution (Breslow and Day, 1987). All cancers other than KS, NHL, and invasive cervical carcinoma were grouped as NADCs. AIDS-defining cancers and NADCs were further combined into an 'all cancers' category.

The IRs among PWHA were also computed separately for the pre-, early-, and late-HAART periods. As the purpose was to make comparisons within the SHCS, IRs were standardised for age (5-year groups) and sex (when appropriate), using the direct method (Breslow and Day, 1987) and the age and sex structure of all PWHA included in this study as a standard population. The 95\% CIs of IRs and of IR ratios in different periods were computed according to the Poisson distribution.

Age-specific IRs (i.e., 25-34, 35-44 and 45-54, and 55-69 years) and corresponding 95\% CIs were computed for selected NADCs separately in two periods (the pre-HAART and the HAART periods). Age-specific IRs were internally standardised for age (5-year groups) and sex (when appropriate) based on the distribution of all PWHA included in this study. For comparison purposes, the corresponding age-specific IRs published for 1998-2002 in the general population from the same Swiss cantons were also computed (Curado et al, 2007).

\section{RESULTS}

Among 9429 SHCS participants followed for a total of 53715 person-years, 858 cancers were identified (Table 1). Observed and expected numbers and corresponding SIRs in the pre-, early-, and late-HAART periods are shown for cancer sites or types with at least two cases observed. The SIRs of KS, NHL, and invasive cervical carcinoma declined by several fold. The SIRs for some individual NADCs (i.e., anus, liver, and non-melanomatous skin) increased between the pre- and early-HAART periods, but not between the early- and late-HAART periods. The SIR for Hodgkin's lymphoma increased greatly between the pre- (9.2) and the early-HAART (21.0) periods, but little thereafter (28.1). The SIRs for cancer of the head and neck and the lung did not change, whereas the SIR for multiple myeloma declined. The SIRs for all NADCs combined did not substantially change by period. The SIR for the combination of all cancers diminished from 17.6 $(95 \% \mathrm{CI}, 16.1-19.1)$ in the pre-HAART to $3.0(95 \% \mathrm{CI}, 2.6-3.6)$ in the late-HAART period (Table 1).

Table 2 is restricted to cancers with $>10$ cases observed after the introduction of HAART. Age-standardised IRs in the pre-, early-, and late-HAART periods with corresponding IR ratios are shown. Large decreases of IRs for KS, NHL, and all cancers were observed between the pre- and early-HAART periods, whereas no significant change was found for NADCs (IR ratio, 1.2; 95\% CI, 0.9-1.7). 
Table I Observed and expected numbers of cancers, SIRs, and 95\% Cls among PWHA by period of cancer diagnosis

\begin{tabular}{|c|c|c|c|c|c|c|c|c|c|}
\hline \multirow[b]{2}{*}{ Cancer site or type (ICDI0) } & \multicolumn{9}{|c|}{ Period } \\
\hline & O/E & SIR & $95 \% \mathrm{Cl}$ & O/E & SIR & $95 \% \mathrm{Cl}$ & O/E & SIR & $95 \% \mathrm{Cl}$ \\
\hline \multicolumn{10}{|l|}{ AIDS-defining cancers } \\
\hline Kaposi's sarcoma (C46) & 272/1.1 & 246 & $218-277$ & $35 / 0.7$ & 47.8 & $33.3-66.6$ & $14 / 0.6$ & 22.9 & $12.5-38.5$ \\
\hline All AIDS-defining cancers & $467 / 3.4$ & 136 & $124-149$ & $89 / 3.2$ & 27.7 & $22.2-34.1$ & $46 / 3.1$ & 14.7 & $10.8-19.6$ \\
\hline \multicolumn{10}{|l|}{ Non-AIDS-defining cancers } \\
\hline Head and neck (COO-CI4, C30-C32) & $9 / 2.1$ & 4.3 & $2.0-8.3$ & $8 / 2.7$ & 2.9 & $1.3-5.8$ & $7 / 3.2$ & 2.2 & $0.9-4.5$ \\
\hline Stomach $(\mathrm{Cl} 6)$ & $1 / 0.7$ & 1.5 & $0.0-8.5$ & $1 / 0.9$ & 1.2 & $0.0-6.7$ & $1 / 1.0$ & 1.0 & $0.0-5.6$ \\
\hline $\begin{array}{l}\text { Small intestine, colon, rectum and rectosigmoid } \\
\text { junction }(\mathrm{Cl} \text {-C2O) }\end{array}$ & $2 / 1.8$ & 1.1 & $0.1-4.0$ & $2 / 2.8$ & 0.7 & $0.1-2.6$ & 1/3.5 & 0.3 & $0.0-1.6$ \\
\hline Skin, non-melanomatous (C44) & $7 / 4.0$ & 1.7 & $0.7-3.6$ & $23 / 6.5$ & 3.5 & $2.2-5.3$ & $23 / 7.0$ & 3.3 & $2.1-4.9$ \\
\hline Breast $(\mathrm{C} 50)^{\mathrm{b}}$ & $1 / 1.7$ & 0.6 & $0.0-3.4$ & $4 / 3.3$ & 1.2 & $0.3-3.2$ & $4 / 4.3$ & 0.9 & $0.2-2.4$ \\
\hline Ovary (C56) & $2 / 0.3$ & 6.4 & $0.6-23.5$ & $0 / 0.4$ & - & - & $0 / 0.5$ & - & - \\
\hline Prostate (C6I) & $0 / 1.1$ & - & - & $5 / 2.8$ & 1.8 & $0.6-4.1$ & $5 / 3.8$ & 1.3 & $0.4-3.1$ \\
\hline Testis (C62) & $4 / 3.0$ & 1.3 & $0.3-3.4$ & $3 / 2.4$ & 1.2 & $0.2-3.7$ & $1 / 1.8$ & 0.5 & $0.0-3.1$ \\
\hline Kidney (C64) & 1/0.5 & 1.9 & $0.0-10.6$ & 1/0.8 & 1.3 & $0.0-7.2$ & $3 / 1.0$ & 3.1 & $0.6-9.2$ \\
\hline Bladder (C67) & $1 / 1.0$ & 1.1 & $0.0-6.0$ & $0 / 1.4$ & - & - & $1 / 1.7$ & 0.6 & $0.0-3.3$ \\
\hline Brain, meninges and central nervous systems (C70-C72) & $2 / 0.9$ & 2.2 & $0.2-7.9$ & $2 / 0.9$ & 2.2 & $0.2-8.0$ & $0 / 1.0$ & - & - \\
\hline Thyroid (C73) & $2 / 0.7$ & 2.9 & $0.3-10.7$ & $1 / 0.8$ & 1.2 & $0.0-7.0$ & $0 / 0.8$ & - & - \\
\hline Hodgkin's lymphoma (C8I) & $7 / 0.8$ & 9.2 & $3.6-19.0$ & $12 / 0.6$ & 21.0 & $10.8-36.8$ & $13 / 0.5$ & 28.1 & $14.9-48.2$ \\
\hline Multiple myeloma (C90) & $3 / 0.2$ & 14.8 & $2.8-43.9$ & $1 / 0.3$ & 3.2 & $0.0-18.1$ & $2 / 0.4$ & 5.1 & $0.5-18.9$ \\
\hline Leukaemias (C91-C95) & |/0.7 & 1.5 & $0.0-8.3$ & $2 / 0.8$ & 2.4 & $0.2-8.8$ & 1/0.9 & 1.1 & $0.0-6.5$ \\
\hline All non-AIDS-defining cancers ${ }^{c}$ & $62 / 26.7$ & 2.3 & $1.8-3.0$ & 100/37.3 & 2.7 & $2.2-3.3$ & $94 / 42.8$ & 2.2 & $1.8-2.7$ \\
\hline
\end{tabular}

Abbreviations: $\mathrm{Cl}=$ confidence intervals; $\mathrm{E}=$ expected; HAART = highly active antiretroviral therapy; $\mathrm{O}=$ observed; $\mathrm{PWHA}=$ people with $\mathrm{HIV}$ or $\mathrm{AIDS}$; $\mathrm{PY}=$ person years; $\mathrm{SIRs}=$ standardised incidence ratios. ${ }^{a}$ Includes nine tongue, six mouth, three larynx cancers, and one cancer each of lip, tonsil, oropharynx, nasopharynx, hypopharynx, and nasal cavity. ${ }^{b}$ Females only. ${ }^{c}$ Also includes four unknown primary sites plus one cancer each of the oesophagus, biliary tract, connective/soft tissue, and corpus uteri.

Table $2 \operatorname{IRs}^{\mathrm{a}}(\times 100000)$, and IR ratios and corresponding 95\% Cls for selected cancers ${ }^{\mathrm{b}}$ among PWHA by period of cancer diagnosis

\begin{tabular}{|c|c|c|c|c|c|c|c|c|c|c|c|}
\hline \multirow[b]{3}{*}{ Cancer site or type (ICDI0) } & \multicolumn{9}{|c|}{ Period } & \multirow[b]{3}{*}{$\begin{array}{l}\text { IR ratio }(95 \% \mathrm{Cl}) \\
\text { early vs pre }\end{array}$} & \multirow[b]{3}{*}{$\begin{array}{l}\text { IR ratio }(95 \% \mathrm{Cl}) \\
\text { late vs early }\end{array}$} \\
\hline & \multicolumn{3}{|c|}{$\begin{array}{c}\text { Pre-HAART } \\
\text { (1985-1996) } \\
20615 \text { PY }\end{array}$} & \multicolumn{3}{|c|}{$\begin{array}{c}\text { Early-HAART } \\
(1997-2001) \\
17690 \mathrm{PY}\end{array}$} & \multicolumn{3}{|c|}{$\begin{array}{c}\text { Late-HAART } \\
(2002-2006) \\
15410 \mathrm{PY}\end{array}$} & & \\
\hline & 0 & IR & $95 \% \mathrm{Cl}$ & 0 & IR & $95 \% \mathrm{Cl}$ & 0 & IR & $95 \% \mathrm{Cl}$ & & \\
\hline \multicolumn{12}{|l|}{ AIDS-defining cancers } \\
\hline All AIDS-defining cancers ${ }^{c}$ & 467 & 2283 & $2075-2505$ & 89 & 442 & $336-566$ & 46 & 163 & $112-226$ & $0.2(0.1-0.3)$ & $0.4(0.2-0.6)$ \\
\hline \multicolumn{12}{|l|}{ Non-AIDS-defining cancers } \\
\hline Head and neck (C00-CI4, C30-C32) & 9 & 41.6 & 18.8-79.3 & 8 & 37.2 & $15.0-75.3$ & 7 & 19.2 & $7.7-39.8$ & $0.9(0.3-2.4)$ & $0.5(0.2-1.4)$ \\
\hline Anus (C2I) & 2 & 8.3 & $0.9-30.1$ & 12 & 42.7 & $21.9-74.7$ & 6 & 25.3 & $7.3-58.8$ & $5.2(1.3-21.3)$ & $0.6(0.2-1.7)$ \\
\hline Liver (C22) & 2 & 9.6 & $1.1-34.7$ & 7 & 25.9 & $10.4-53.5$ & 5 & 17.1 & $5.1-40.9$ & $2.7(0.5-13.9)$ & $0.7(0.2-2.1)$ \\
\hline All cancers & 529 & 2602 & $2379-2840$ & 189 & 839 & $704-990$ & 140 & 487 & $395-590$ & $0.3(0.3-0.4)$ & $0.6(0.4-0.8)$ \\
\hline
\end{tabular}

Abbreviations: $\mathrm{Cl}=$ confidence interval; $\mathrm{HAART}=$ highly active antiretroviral therapy; $\mathrm{IR}=$ incidence rate; $\mathrm{O}=$ observed; $\mathrm{PWHA}=$ people with $\mathrm{HIV}$ or $\mathrm{AIDS}$; $\mathrm{PY}=$ person years. ${ }^{a}$ Rates are standardised by 5 -year age group and sex, based on the age and sex distribution of all PWHA included in this study; ${ }^{\mathrm{b}} \mathrm{Cancers}$ diagnosed in $>10$ PWHA in the HAART period; ' Including cervix uteri (C53). 
Increases were observed, however, from the pre- to early-HAART period, for cancer of the anus (IR ratio, 5.2; 95\% CI, 1.3-21.3) and non-melanomatous skin cancer (IR ratio, 2.4; 95\% CI, 1.0-5.7). When IRs of selected cancers in the early- and late-HAART periods were compared, additional declines in KS (IR ratio, 0.3 ; $95 \% \mathrm{CI}$, $0.2-0.7$ ), NHL (IR ratio, $0.4 ; 95 \% \mathrm{CI}, 0.2-0.6$ ) and all cancers (IR ratio, $0.6 ; 95 \% \mathrm{CI}, 0.4-0.8$ ) were found. The IR ratios (late- $v s$ early-HAART period) for individual NADCs or their combinations were close to unity (lung, non-melanomatous skin, Hodgkin's lymphoma) or non-significantly below unity (head and neck, anus and liver) (Table 2).
Figure 1 shows the steep downward trends in the IRs for all cancers, by gender. Decreases were greater among men than women and among men having sex with men than heterosexuals and intravenous drug users. The IRs for all cancers in the two sexes and in the three HIV-transmission categories became similar in the late-HAART period (Figure 1).

Age-specific IRs for cancer of the anus, liver, lung, nonmelanomatous skin, Hodgkin's lymphoma, and all NADCs combined in PWHA in the pre-HAART and the HAART periods, and, for comparison purposes, in the general population (1998-2002), are shown in Figure 2. Cancer cases were extremely
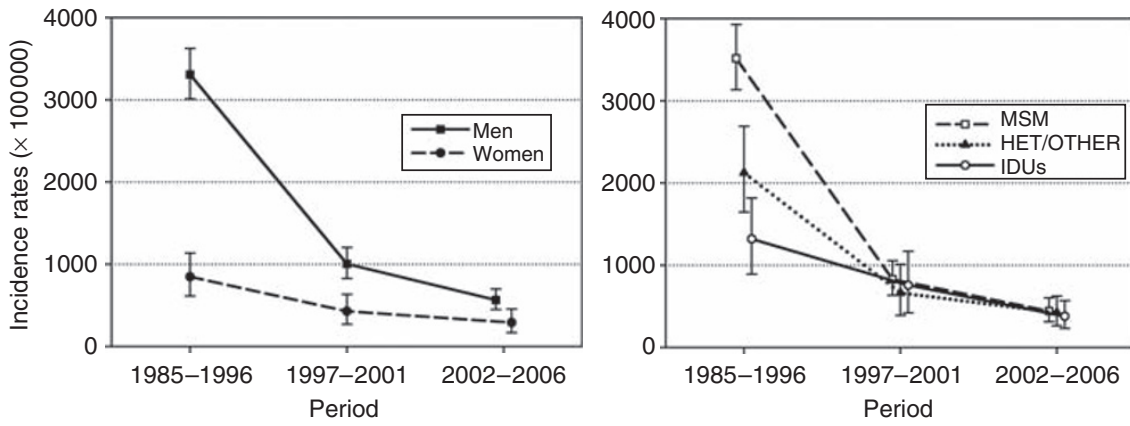

Figure I Incidence rates (standardised by 5-year age group and, when appropriate, sex, based on the age and sex distribution of all people with HIV or AIDS (PWHA) included in this study) and corresponding 95\% confidence intervals of all cancers among PWHA by sex or HIV-transmission category and period of cancer diagnosis. MSM, men having sex with men; HET, heterosexual; IDU, intravenous drug user.

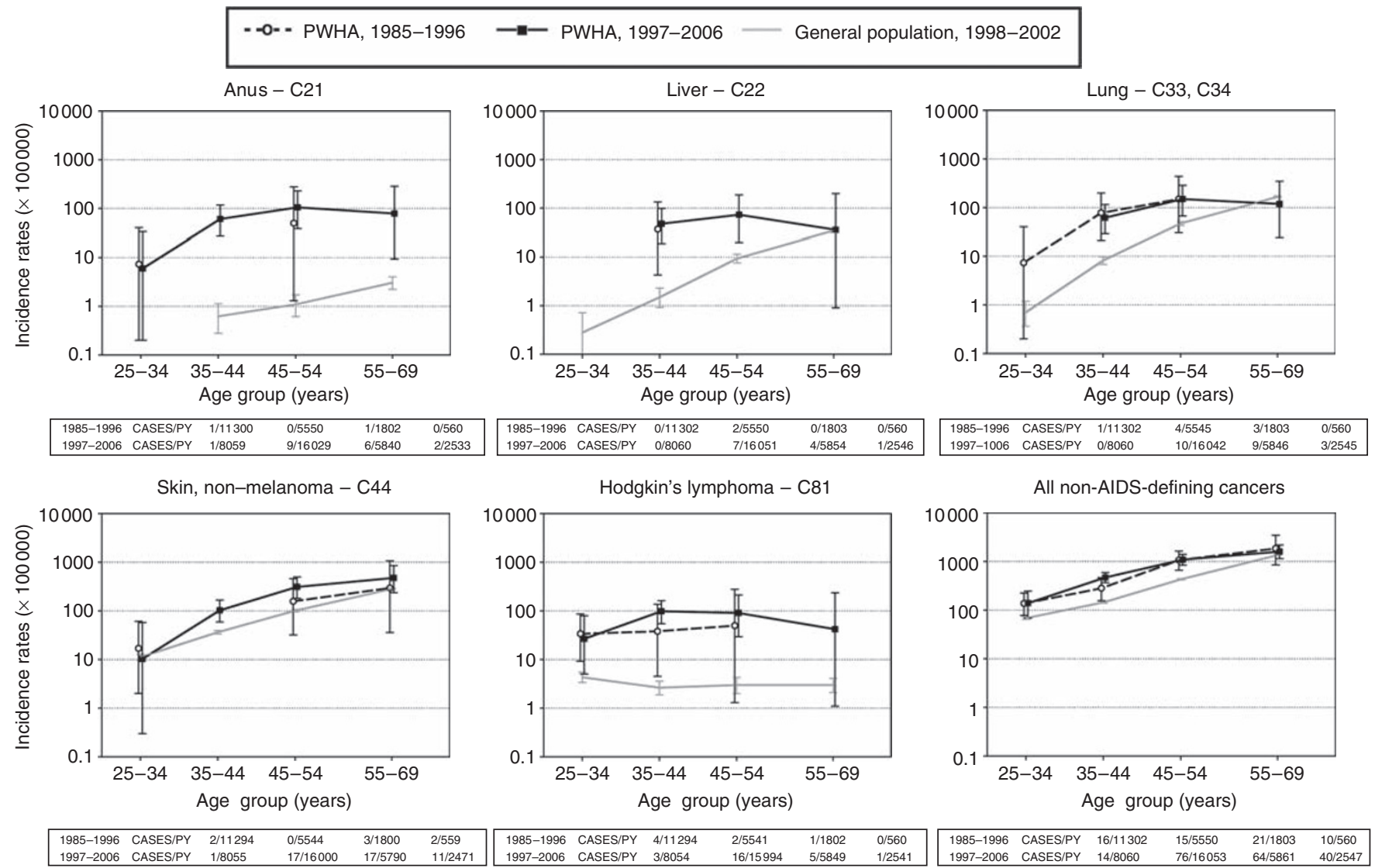

Figure 2 Age-specific incidence rates of selected cancers among people with HIV or AIDS (PWHA) and the general population from the same Swiss Cantons (age-standardised as in Figure I) by period of cancer diagnosis. PY, person-years. 
few in the pre-HAART period, especially in PWHA aged $\geqslant 35$ years. The $95 \%$ CIs of age-specific IRs for individual NADCs in PWHA in the pre-HAART and HAART periods always overlapped. In the HAART periods, 95\% CIs of IRs for cancer of the anus, liver, lung, non-melanomatous skin, Hodgkin's lymphoma, and all NADCs combined did not overlap with IRs from the general population in the 35-44- and 45-54-year age groups. In the 55-69year age group, only for anal cancer did the IR in the HAART periods not overlap with the corresponding IR in the general population (Figure 2).

\section{DISCUSSION}

In this paper, we used SIRs to compare cancer excess in PWHA with that in previous studies (Clifford et al, 2005; van Leeuwen et al, 2009; Dal Maso et al, 2009), and IRs to evaluate cancer trends within the SHCS. Trends in cancer incidence in SHCS participants in the last two decades has been dominated by the favourable trends in KS and NHL. All cancer incidence (including both AIDS-defining cancers and NADCs) decreased in the late-HAART period by $81 \%$ compared with the pre-HAART period. Furthermore, mainly because of the decline in KS, previously large differences in cancer incidence between men and women, as well as between men having sex with men, heterosexuals, and intravenous drug users, have disappeared.

Further decreases in the incidence of KS and NHL also emerged between the early- and late-HAART periods. In the late-HAART period, treatment options increased and the risk of untreated viraemia became better appreciated than before (Hammer et al, 2008). Virological and immunological outcomes of initial HAART improved between 2000-2001 and 2004-2005 in the SHCS (Vo et al, 2008). Indeed, a higher proportion of KS and NHL occurred in HAART-naïve PWHA in the early-HAART (46\%) than in the late-HAART $(27 \%)$ period (data not shown).

This study also showed that the incidence of all NADCs combined did not increase between the pre-HAART and HAART periods, even though by the late-HAART period it had become higher than the declining incidence of KS and NHL combined. In other studies using differently defined populations (e.g., HIVpositive people or people with AIDS only) and different statistical approaches (SIR or age-standardised IRs), increases in NADCs have been reported since the introduction of HAART (Engels et al, 2008; Patel et al, 2008; Dal Maso et al, 2009; Guiguet et al, 2009; van Leeuwen et al, 2009), especially for cancer of the anus (Piketty et al, 2008; Chaturvedi et al, 2009), liver (Rosenthal et al, 2007; Polesel et al, 2010), lung (Bower et al, 2003; Kirk et al, 2007), and Hodgkin's lymphoma (Biggar et al, 2006). Thus, concerns have been raised that HAART or its consequences (immune reconstitution) may have directly contributed to the increase of certain NADCs (Hammer et al, 2008).

Drugs included in HAART have been attributed to both carcinogenic (e.g., incorporation of zidovudine into nuclear DNA and alteration of the expression of several cell-cycle genes) (Olivero, 2007) and anti-tumour (anti-angiogenic effect of protease inhibitors) (Monini et al, 2004) effects. Zidovudine and zalcitabine have been classified in an International Agency for Research on Cancer Monograph (IARC, 2000) as 'possibly carcinogenic to humans' on the basis of inadequate evidence in humans, but sufficient evidence of carcinogenicity in experimental animals (IARC, 2000). The hepatotoxicity of HAART was suspected to worsen the effect of hepatitis $B$ and $C$ infection on the risk of liver cancer (Puoti et al, 2004). Hodgkin's lymphoma was reported to occur more frequently in AIDS patients with moderate than severe immunosuppression in the United States (Biggar et al, 2006), as well as among those using non-nucleoside reverse transcription inhibitors in the United Kingdom (Powles et al, 2009). The possibility of some adverse effect of HAART on cancer risk will be raised again, and it is therefore important to use adequate monitoring tools to account for the concurrent dramatic increase in the life expectancy of PHWA (Polesel et al, 2010).

The SIRs for a few NADCs (anus, liver, non-melanomatous skin, and Hodgkin's lymphoma) increased in the SHCS after the introduction of HAART. At the same time, however, SHCS participants had grown older (the proportion of person-years from PWHA aged $\geqslant 35$ years had increased from $38 \%$ in the pre-, to $67 \%$ in the early-, and $81 \%$ in the late-HAART period).

The SIRs, however, are based on the indirect adjustment method, meaning that a standard population (the general Swiss population) provides the rates, and the study population (PWHA) provides the weights (age and sex structure) (Schoenbach, 2000). Hence, if the PWHA age structure changes substantially, the comparison of SIRs over time becomes problematic. Using, more correctly, IRs age-standardised by the direct method (the application of age-specific IRs among PWHA in different periods to the age and sex structure of the same standard population, i.e., PWHA over the entire study), cancers of the anus and nonmelanomatous skin were the only malignancies to increase significantly, and only between the pre- and the early-HAART periods in the SHCS. Although the direct method gives greater comparability, it requires more data than the indirect method (Schoenbach, 2000). Therefore, even for the most frequent NADCs, the low number of cancer cases made the standardisation process unstable. Indeed, the 95\% CI of age-specific IRs in PWHA in the pre-HAART and HAART periods broadly overlapped for individual NADCs, as well as for all NADCs combined.

Five individual NADCs showed a clear excess in the HAART periods among PWHA compared with the general population, regardless of statistical approach. Three of these NADCs (anus, liver, and Hodgkin's lymphoma) have a well-established viral aetiology (human papillomavirus (IARC, 2007), hepatitis B and C viruses (IARC, 1994), and Epstein-Barr virus (IARC, 1997), respectively). Contrary to $\mathrm{KS}$ and some types of NHL, a long latent period separates the infection with the responsible virus and the onset of cancer of the anus and liver. A viral aetiology for nonmelanomatous skin cancer is not yet well established, except for the rare polyomavirus-associated Merkel cell carcinoma (Lanoy et al, 2009). Previous studies suggested that smoking could not totally account for the increases in lung cancer (The D:A:D Study Group, 2006; Chaturvedi et al, 2007), and that impaired immunity was associated with liver disease and liver cancer among PWHA infected with hepatitis B and C viruses (Clifford et al, 2008). The effect of HIV-related immunodeficiency on cancers of the lung and liver remains, however, ill-defined (Bouvard et al, 2009).

The SHCS has many strengths, including the length and completeness of follow-up and the good representation of women and different HIV-transmission categories (The Swiss HIV Cohort Study, 2010). Furthermore, the SHCS has been estimated to cover $45 \%$ of the cumulative number of HIV infections declared to the Swiss health authorities and $69 \%$ of registered AIDS cases, making the study unique in terms of population representativeness. The possibility of record linkage with high-quality cancer registries improved the completeness and quality of cancer-related information (e.g., histological confirmation) beyond what was available in the SHCS records.

The most important limitations of this study are 1) the relatively small number of individual NADCs, and 2) the complexity of adjusting for large decreases in competing non-cancer risks among PWHA (Keiser et al, 2004) without making implausible assumptions about the way removal of competing risks would have affected cancer risk (Rothman et al, 2008). Problems typical of record-linkage studies, for example, inaccuracies in personal identifiers and self-reported legal residence that may result in some undermatching between the SHCS participants and cancer registry records, cannot be completely excluded, but should have been largely avoided. With respect to surveillance bias, no 
difference was found in the risk of cancers in which screening can make a substantial difference (e.g., cancer of the colon-rectum, breast, prostate, and thyroid). Part of the excess of cancer of the anus and non-melanomatous skin, however, may be due to a more intense search and more accurate diagnosis of these cancers in PWHA than in the general population.

In conclusion, our study showed that the incidence of KS and NHL continued to decline from the early- to the late-HAART period, but the incidence of NADCs did not change substantially. Estimates of the excess of cancers of the anus, liver, lung, nonmelanomatous skin and Hodgkin's lymphoma in PWHA compared with the general population (expressed as SIRs or age-specific IRs) became more precise in the HAART periods. Comparisons of the incidence of NADCs among PWHA in the pre-HAART and HAART periods remained very difficult, but they did not support claims of an adverse influence of HAART per se or HAART-related immune reconstitution on cancer risk.

\section{REFERENCES}

Ancelle-Park R (1993) Expanded European AIDS case definition. Lancet 341: 441

Biggar RJ, Jaffe ES, Goedert JJ, Chaturvedi A, Pfeiffer R, Engels EA (2006) Hodgkin's lymphoma and immunodeficiency in persons with HIV/AIDS. Blood 108: 3786-3791

Bouvard V, Baan R, Straif K, Grosse Y, Secretan B, El Ghissassi F, Benbrahim-Tallaa L, Guha N, Freeman C, Galichet L, Cogliano V (2009) A review of human carcinogens - Part B: biological agents. Lancet Oncol 10: $321-322$

Bower M, Powles T, Nelson M, Shah P, Cox S, Mandelia S, Gazzard B (2003) HIV-related lung cancer in the era of highly active antiretroviral therapy. AIDS 17: $371-375$

Breslow NE, Day NE (1987) Statistical Methods in Cancer Research. Vol. II: The design and analysis of cohort studies. IARC Scientific Publications No. 82 International Agency for Research on Cancer: Lyon

Chaturvedi AK, Madeleine MM, Biggar RJ, Engels EA (2009) Risk of human papillomavirus-associated cancers among persons with AIDS. J Natl Cancer Inst 101: 1120-1130

Chaturvedi AK, Pfeiffer RM, Chang L, Goedert JJ, Biggar RJ, Engels EA (2007) Elevated risk of lung cancer among people with AIDS. AIDS 21: $207-213$

Clifford GM, Polesel J, Rickenbach M, Dal Maso L, Keiser O, Kofler A, Rapiti E, Levi F, Jundt G, Fisch T, Bordoni A, De Weck D, Franceschi S, Swiss HIV Cohort Study (2005) Cancer risk in the Swiss HIV Cohort Study: associations with immunodeficiency, smoking, and highly active antiretroviral therapy. J Natl Cancer Inst 97: 425-432

Clifford GM, Rickenbach M, Polesel J, Dal Maso L, Steffen I, Ledergerber B, Rauch A, Probst-Hensch NM, Bouchardy C, Levi F, Franceschi S, Swiss HIV Cohort Study (2008) Influence of HIV-related immunodeficiency on the risk of hepatocellular carcinoma. AIDS 22: 2135-2141

Curado MP, Edwards B, Shin HR, Storm H, Ferlay J, Heanue M, Boyle P (2007) Cancer Incidence in Five Continents. Vol. IX. IARC Scientific Publication No. 160 International Agency for Research on Cancer: Lyon

Dal Maso L, Braga C, Franceschi S (2001) Methodology used for 'software for automated linkage in Italy' (SALI). J Biomed Inform 34: $387-395$

Dal Maso L, Polesel J, Serraino D, Lise M, Piselli P, Falcini F, Russo A, Intrieri T, Vercelli M, Zambon P, Tagliabue G, Zanetti R, Federico M, Limina RM, Mangone L, De Lisi V, Stracci F, Ferretti S, Piffer S, Budroni M, Donato A, Giacomin A, Bellù F, Fusco M, Madeddu A, Vitarelli S, Tessandori R, Tumino R, Suligoi B, Franceschi S; for the Cancer and AIDS Registries Linkage (CARL) Study (2009) Pattern of cancer risk in persons with AIDS in Italy in the HAART era. Br J Cancer 100: 840-847

Engels EA, Biggar RJ, Hall HI, Cross H, Crutchfield A, Finch JL, Grigg R, Hylton T, Pawlish KS, McNeel TS, Goedert JJ (2008) Cancer risk in people infected with human immunodeficiency virus in the United States. Int J Cancer 123: 187-194

Franceschi S, Dal Maso L, Rickenbach M, Polesel J, Hirschel B, Cavassini M, Bordoni A, Elzi L, Ess S, Jundt G, Mueller N, Clifford GM, The Swiss HIV Cohort Study (2008) Kaposi sarcoma incidence in the Swiss HIV Cohort

\section{ACKNOWLEDGEMENTS}

This study has been performed in the framework of the Swiss HIV Cohort Study, supported by the Swiss National Science Foundation, and was funded by grants from OncoSuisse (ICP OCS 0135503-2003); The Swiss Cancer League (KFS 02478-08-2009); and the Istituto Superiore di Sanità, (Grant 20 G.3). During the work on this paper, Mr Mauro Lise was the recipient of a fellowship from the Associazione Italiana per la Ricerca sul Cancro carried out at the International Agency for Research on Cancer. We thank Jerry Polesel, Aviano Cancer Center, Aviano, Italy, for technical support and Trudy Perdrix-Thoma, International Agency for Research on Cancer, Lyon, France, for editorial support.

\section{Conflict of interest}

The authors declare no conflict of interest.
Study before and after highly active antiretroviral therapy. $\mathrm{Br} J$ Cancer 99: $800-804$

Fritz A, Percy C, Jack A, Shanmugaratnam K, Sobin L, Parkin DM, Whelan S (2000) International Classification of Diseases for Oncology. Third edition World Health Organization: Geneva

Guiguet M, Boué F, Cadranel J, Lang JM, Rosenthal E, Costagliola D (2009) Effect of immunodeficiency, HIV viral load, and antiretroviral therapy on the risk of individual malignancies (FHDH-ANRS CO4): a prospective cohort study. Lancet Oncol 10: $1152-1159$

Hammer SM, Eron Jr JJ, Reiss P, Schooley RT, Thompson MA, Walmsley S, Cahn P, Fischl MA, Gatell JM, Hirsch MS, Jacobsen DM, Montaner JS, Richman DD, Yeni PG, Volberding PA (2008) Antiretroviral treatment of adult HIV infection: 2008 recommendations of the International AIDS Society-USA panel. JAMA 300: 555-570

IARC (1994) Monographs on the Evaluation of Carcinogenic Risks to Humans Volume 59: Hepatitis Viruses. International Agency for Research on Cancer: Lyon

IARC (1997) Monographs on the Evaluation of Carcinogenic Risks to Humans Volume 70: Epstein-Barr Virus and Kaposi's Sarcoma Herpesvirus/Human Herpesvirus 8. International Agency for Research on Cancer: Lyon

IARC (2000) Monographs on the Evaluation of Carcinogenic Risks to Humans Volume 76: Some Antiviral and Antineoplastic Drugs, and Other Pharmaceutical Agents. International Agency for Research on Cancer: Lyon

IARC (2007) Monographs on the Evaluation of Carcinogenic Risks to Humans Volume 90: Human Papillomaviruses. International Agency for Research on Cancer: Lyon

Keiser O, Taffe P, Zwahlen M, Battegay M, Bernasconi E, Weber R, Rickenbach M (2004) All cause mortality in the Swiss HIV Cohort Study from 1990 to 2001 in comparison with the Swiss population. AIDS 18: $1835-1843$

Kirk GD, Merlo C, O'Driscoll P, Mehta SH, Galai N, Vlahov D, Samet J, Engels EA (2007) HIV infection is associated with an increased risk for lung cancer, independent of smoking. Clin Infect Dis 45: 103-110

Lanoy E, Dores GM, Madeleine MM, Toro JR, Fraumeni Jr JF, Engels EA (2009) Epidemiology of nonkeratinocytic skin cancers among persons with AIDS in the United States. AIDS 23: 385-393

Ledergerber B, Telenti A, Egger M, for the Swiss HIV Cohort Study (1999) Risk of HIV related Kaposi's sarcoma and non-Hodgkin's lymphoma with potent antiretroviral therapy: prospective cohort study. BMJ 319: $23-24$

Monini P, Sgadari C, Toschi E, Barillari G, Ensoli B (2004) Antitumour effects of antiretroviral therapy. Nat Rev Cancer 4: 861-875

Olivero OA (2007) Mechanisms of genotoxicity of nucleoside reverse transcriptase inhibitors. Environ Mol Mutagen 48: 215-223

Parkin DM, Muir C, Whelan S, Gao YT, Ferley J, Powell J (1992) Cancer Incidence in Five Continents. Vol. VI. IARC Scientific Publications No. 120 International Agency for Research on Cancer: Lyon

Parkin DM, Whelan SL, Ferlay J, Raymond L, Young J (1997) Cancer Incidence in Five Continents. Vol. VII. IARC Scientific Publications No. 143 International Agency for Research on Cancer: Lyon 
Parkin DM, Whelan SL, Ferlay J, Thomas DB, Teppo L (2002) Cancer Incidence in Five Continents. Volume VIII. IARC Scientific Publications No. 155 International Agency for Research on Cancer: Lyon

Patel P, Hanson DL, Sullivan PS, Novak RM, Moorman AC, Tong TC, Holmberg SD, Brooks JT (2008) Incidence of types of cancer among HIV-infected persons compared with the general population in the United States, 1992 -2003. Ann Intern Med 148: 728-736

Piketty C, Selinger-Leneman H, Grabar S, Duvivier C, Bonmarchand M, Abramowitz L, Costagliola D, Mary-Krause M (2008) Marked increase in the incidence of invasive anal cancer among HIV-infected patients despite treatment with combination antiretroviral therapy. AIDS 22: $1203-1211$

Polesel J, Clifford GM, Rickenbach M, Dal Maso L, Battegay M, Bouchardy C, Furrer H, Hasse B, Levi F, Probst-Hensch NM, Schmid P, Franceschi S, The Swiss HIV Cohort Study (2008) Non-Hodgkin lymphoma incidence in the Swiss HIV Cohort Study before and after highly active antiretroviral therapy. AIDS 22: $301-306$

Polesel J, Franceschi S, Suligoi B, Crocetti E, Falcini F, Guzzinati S, Vercelli M, Zanetti R, Tagliabue G, Russo A, Luminari S, Stracci F, De Lisi V, Ferretti $S$, Mangone L, Budroni M, Limina RM, Piffer S, Serraino D, Bellù F, Giacomin A, Donato A, Madeddu A, Vitarelli S, Fusco M, Tessandori R, Tumino R, Piselli P, Dal Maso L; for the Cancer and AIDS Registries Linkage (CARL) Study (2010) Cancer incidence in people with AIDS in Italy. Int J Cancer; e-pub ahead of print 4 January 2010

Powles T, Robinson D, Stebbing J, Shamash J, Nelson M, Gazzard B, Mandelia S, Moller H, Bower M (2009) Highly active antiretroviral therapy and the incidence of non-AIDS-defining cancers in people with HIV infection. J Clin Oncol 27: 884-890

Puoti M, Bruno R, Soriano V, Donato F, Gaeta GB, Quinzan GP, Precone D, Gelatti U, Asensi V, Vaccher E (2004) Hepatocellular carcinoma in HIVinfected patients: epidemiological features, clinical presentation and outcome. AIDS 18: 2285-2293

\section{Appendix}

The members of the Swiss HIV Cohort Study are M Battegay, E Bernasconi, J Böni, HC Bucher, P Bürgisser, A Calmy, M Cavassini, R Dubs, M Egger, L Elzi, M Fischer, M Flepp, A Fontana, P Francioli (President of the SHCS), H Furrer (Chairman of the Clinical and Laboratory Committee), CA Fux, M Gorgievski, HF Günthard
Rosenthal E, Pialoux G, Bernard N, Pradier C, Rey D, Bentata M, Michelet C, Pol S, Perronne C, Cacoub P (2007) Liver-related mortality in humanimmunodeficiency-virus-infected patients between 1995 and 2003 in the French GERMIVIC Joint Study Group Network (MORTAVIC 2003 Study). J Viral Hepat 14: 183-188

Rothman KJ, Greenland S, Lash TL (2008) Modern Epidemiology. Third edn, pp 55-56. Lippincott Williams \& Wilkins: Philadelphia

Schoenbach VJ (2000) Chapter 6: Standardization of rates and ratios. In: Understanding the Fundamentals of Epidemiology: An Evolving Text. Schoenbach VJ, Rosamund WD (eds) pp 129-151. University of North Carolina at Chapel Hill: Chapel Hill, (available from http://www. epidemiolog.net/evolving/Standardization.pdf)

The Collaboration of Observational HIV Epidemiological Research Europe (COHERE) Study Group (2009) Incidence and risk factors of HIVrelated non-Hodgkin's lymphoma in the era of combination antiretroviral therapy: a European multicohort study. Antivir Ther 14: $1065-1074$

The D:A:D Study Group (2006) Liver-related deaths in persons infected with the human immunodeficiency virus: the D:A:D study. Arch Intern Med 166: $1632-1641$

The Swiss HIV Cohort Study (2010) Cohort Profile: the Swiss HIV Cohort Study. Int J Epidemiol; e-pub ahead of print 30 November 2009

van Leeuwen MT, Vajdic CM, Middleton MG, McDonald AM, Law M, Kaldor JM, Grulich AE (2009) Continuing declines in some but not all HIV-associated cancers in Australia after widespread use of antiretroviral therapy. AIDS 23: $2183-2190$

Vo TT, Ledergerber B, Keiser O, Hirschel B, Furrer H, Battegay M, Cavassini M, Bernasconi E, Vernazza P, Weber R (2008) Durability and outcome of initial antiretroviral treatments received during 2000-2005 by patients in the Swiss HIV Cohort Study. J Infect Dis 197: 1685-1694 World Health Organisation (1992) International Statistical Classification of Disease and Related Health Problems. 10th revision WHO: Geneva

(Chairman of the Scientific Board), HH Hirsch, B Hirschel, I Hösli, C Kahlert, L Kaiser, U Karrer, C Kind, T Klimkait, B Ledergerber, G Martinetti, B Martinez de Tejada, N Müller, D Nadal, F Paccaud, G Pantaleo, A Rauch, S Regenass, M Rickenbach (Head of Data Center), C Rudin (Chairman of the Mother and Child Substudy), P Schmid, D Schultze, F Schöni-Affolter, J Schüpbach, R Speck, $\mathrm{P}$ Taffé, A Telenti, A Trkola, P Vernazza, R Weber, and S Yerly. 